\title{
The evolution of intraoperative support in lung transplantation: Cardiopulmonary bypass to extracorporeal membrane oxygenation
}

\author{
P. Michael McFadden, MD, and Christina L. Greene, MD
}

See related article on pages 1152-7.

The report of the first successful clinical heart-lung transplant by Reitz and colleagues ${ }^{1}$ at Stanford, and those that followed, ${ }^{2}$ ushered in a new enthusiasm for lung transplantation. It was soon recognized that lung transplantation was possible without concomitant heart transplantation, and en bloc double lung transplantation using cardiopulmonary bypass soon evolved.

Machuca and colleagues ${ }^{3}$ of the University of Toronto compare outcomes of intraoperative extracorporeal membrane oxygenation (ECMO) versus cardiopulmonary bypass (CPB) support in patients undergoing lung transplantation (LTx). This study is the first to address which method of extracorporeal intraoperative support may be superior in LTx, a topic of intense current interest. The matched cohorts (33 ECMO vs 66 CPB) resulted from a 7-year (2007-2013) review of 673 LTxs performed at their Toronto program. Although retrospective and nonrandomized, the study groups are well matched and adequately powered; inclusion and exclusion criteria are sufficiently defined.

The contemporary period of LTx began in the late 1980s, following a critical assessment of experimental and clinical results of en bloc double LTx, commonly performed at that time. $^{4-6}$ These investigators determined that en bloc "double" LTx, utilizing a central tracheal anastomosis, was technically feasible but frequently attended with severe airway complications, including dehiscence, necrosis, mediastinitis, sepsis, stenosis, and poor longterm survival. To address this problem, a technical alteration in the airway anastomotic technique was introduced. The en bloc tracheal anastomosis was abandoned for a more easily mastered bilateral sequential bronchial anastomosis. This approach avoided the need for CPB in many patients, reduced postoperative hemorrhage, and practically eliminated the life-threatening complications of airway necrosis and dehiscence. Bilateral sequential LTx, with or

From the Division of Cardiothoracic Surgery, Keck School of Medicine of the University of Southern California, Los Angeles, Calif.

Disclosures: Authors have nothing to disclose with regard to commercial support.

Received for publication Dec 4, 2014; accepted for publication Dec 5, 2014; available ahead of print Jan 25, 2015

Address for reprints: P. Michael McFadden, MD, Division of Cardiothoracic Surgery, Department of Surgery, Keck School of Medicine, University of Southern California, Los Angeles, CA 90033 (E-mail: Michael.McFadden@med.usc.edu).

J Thorac Cardiovasc Surg 2015;149:1158-60

$0022-5223 / \$ 36.00$

Copyright (c) 2015 by The American Association for Thoracic Surgery

http://dx.doi.org/10.1016/j.jtcvs.2014.12.020 without CPB, quickly became the procedure of choice for double lung replacement. ${ }^{7-9}$

Subsequent studies examined predictors and indicators for CPB in LTx but found no reliable preoperative predictors for its use. ${ }^{10}$ A recent comparison of 259 single LTxs, 53 $(20.5 \%)$ with and 206 without CPB, revealed that although postoperative bleeding and transfusion requirements were greater with $\mathrm{CPB}$, postoperative lung function and time to extubation were similar. ${ }^{11}$ A subsequent univariate and multivariate analysis by Weber and colleagues ${ }^{12}$ reviewed the association of intraoperative transfusion of packed red cells and fresh frozen plasma with mortality in 134 LTx recipients. A significant increase in mortality was observed in recipients receiving packed red cells and fresh frozen plasma (odds ratio, $1.10, P=.02$; and odds ratio, $1.09, P=.03$, respectively). In recipients who received $>4$ packed red cells, multivariate and univariate analyses showed a hazard ratio of 3.8 (range, 1.4-10.3, $P=.003$ ). Nonsurvivors showed an increase in renal replacement need, primary graft dysfunction, postoperative ECMO support, multisystem organ failure, infection, sepsis, intensive care-unit readmission, and retransplantation.

The subsequent evolution in extracorporeal support brings us to the issue of arteriovenous ECMO (Figure 1), addressed here by Machuca and colleagues ${ }^{3}$ and others. ${ }^{13}$ The current study was undertaken to evaluate the lesscomplex technique of ECMO in LTx. Inherent in ECMO use is a reduction in the following: heparin requirement, prime volume, perioperative bleeding, and transfusion requirement. Based on the report by Weber and colleagues, ${ }^{12}$ postoperative morbidity and mortality would be expected to be lower in LTx patients supported on ECMO than they are in CPB patients.

The current study demonstrates that the intraoperative and 72-hour postoperative requirement for blood transfusion significantly favors the ECMO group. Results showed no statistical difference in the requirement for postoperative ECMO, renal dialysis, re-exploration for bleeding, 90-day mortality, or 12-month Kaplan-Meier survival. The authors have adopted arteriovenous ECMO as their primary method of intraoperative support for LTx.

The next evolution in intraoperative ECMO support for LTx will most likely rest on the ability of veno-venous ECMO to provide adequate oxygenation and support while avoiding the requirement for arterial cannulation. No study to date has addressed its utility in LTx. If veno-venous ECMO is found to be beneficial, and the indications for its application in LTx are well defined, a further evolution 


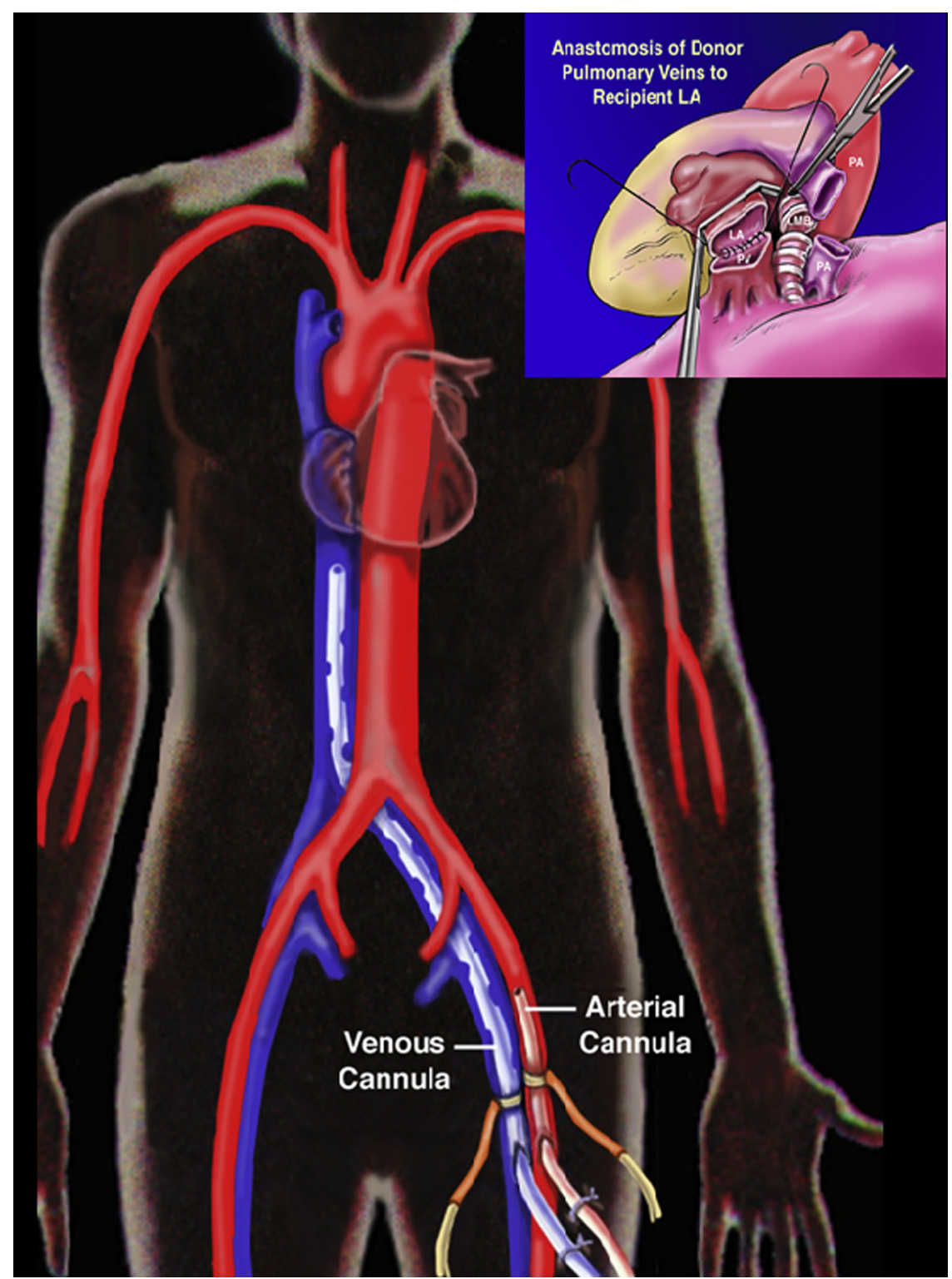

FIGURE 1. Illustration of arteriovenous extracorporeal membrane oxygenation, as used by Machuca and colleagues, ${ }^{1}$ in lung transplantation. Inset is an illustration of the recipient-left atrium to donor-pulmonary vein anastomosis used in lung transplantation. $L A$, Left atrium.

may be to a singular double-lumen veno-venous ECMO cannulation, as has been used for a bridge to transplantation, in acute respiratory distress syndrome, and recently in pulmonary resections in patients with severely compromised pulmonary function. ${ }^{14}$

It must be emphasized that the majority of single LTxs, and many bilateral sequential LTxs, can be performed without the use of any extracorporeal circulatory lung support. Such an approach remains the most desirable, when possible, but it requires competent and attentive anesthesia management. When ECMO is required, facilitated conversion to CPB is mandatory. Conditions that commonly necessitate this conversion include serious bleeding, circulatory insufficiency, and complications in which full circulatory support is needed for management of right or left heart dysfunction and unanticipated concomitant cardiac intervention.

\section{References}

1. Reitz BA, Wallwork JL, Hunt SA, Pennock JL, Billingham ME, Oyer PE, et al. Heart-lung transplantation: successful therapy for patients with pulmonary vascular disease. $N$ Engl J Med. 1982;306:557-64.

2. Jamieson SW, Baldwin J, Stinson EB, Reitz BA, Oyer PE, Hunt S, et al. Clinical heart-lung transplantiation. Transplantation. 1984;37:81-4.

3. Machuca TN, Collaud S, Mercier O, Cheung M, Cunningham V, Kim SJ, et al. Outcomes of intraoperative ECMO versus cardiopulmonary bypass for lung transplantation. J Thorac Cardiovasc Surg. 2015;149:1152-7.

4. Patterson GA, Cooper JD, Dark JH, Jones MT. Experimental and clinical double lung transplantation. J Thorac Cardiovasc Surg. 1988;95:70-4.

5. Patterson GA, Todd TR, Cooper JD, Pearson FG, Winton TL, Maurer J. Airway complications after double lung transplantation. Toronto Lung Transplant Group. J Thorac Cardiovasc Surg. 1990;99:14-20. 
6. Pasque MK, Cooper JD, Kaiser LR, Haydock DA, Triantafillou A, Trulock EP. Improved technique for bilateral lung transplantation: rationale and initial clinical experience. Ann Thorac Surg. 1990;49:785-91.

7. Kaiser LR, Pasque MK, Trulock EP, Low DE, Dresler CM, Cooper JD. Bilateral sequential lung transplantation: the procedure of choice for double-lung replacement. Ann Thorac Surg. 1991;52:438-45.

8. Meyers BF, Patterson GA. Technical aspects of adult lung transplantation. Semin Thorac Cardiovasc Surg. 1998;10:213-20.

9. Mendeloff EN, Huddleston CB, Mallory GB, Trulock EP, Cohen AH, Sweet SC, et al. Pediatric and adult lung transplantation for cystic fibrosis. J Thorac Cardiovasc Surg. 1998;115:404-13.

10. Triantafillou AN, Pasque MK, Huddleston CB, Pond CG, Cerza RF, Forstot RM, et al. Predictors, frequency, and indications for cardiopulmonary bypass during lung transplantation in adults. Ann Thorac Surg. 1994;57:1248-51.
11. Burdett C, Butt T, Lordan J, Dark JH, Clark SC. Comparison of single lung transplant with and without the use of cardiopulmonary bypass. Interact Cardiovasc Thorac Surg. 2012;15:432-6.

12. Weber D, Cottini SR, Locher P, Wenger U, Stehberger PA, Fasshauer M, et al. Association of intraoperative transfusion of blood products with mortality in lung transplant recipients. Perioper Med. 2013;2:20.

13. Ius F, Kuehn C, Tudorache I, Sommer W, Avsar M, Boethig D, et al. Lung transplantation on cardiopulmonary support: venoarterial extracorporeal membrane oxygenation outperformed cardiopulmonary bypass. J Thorac Cardiovasc Surg. 2012;144:1510-6.

14. Bassum R, Semik M, Dickgreber N, Ziegeler S, Fischer S. Single site cannulation veno-venous extracorporeal lung support during pulmonary resection in patients with severely compromised pulmonary function. ASAIO J. December 14, 2014 [Epub ahead of print]. 